\title{
Tonsillitis and Their Complications: Epidemiological, Clinical and Therapeutic Profiles
}

\author{
Abdoul Wahab Haidara1, Youssouf Sidibé1*, Djibril Samaké2, Amady Coulibaly3, \\ Mamadou Karim Touré4, Bréhima Bolonpé Coulibaly4, Siaka Soumaoro5, Boubacary Guindo5, \\ Kassim Diarra5, Kalifa Coulibaly5, Boubacar Sanogo', Mohamed Kéïta ${ }^{4}$, \\ Alhousseini Ag Mohamed ${ }^{4}$
}

\author{
${ }^{1}$ ENT and Head and Neck Surgery Department, CHU Mother-Child "Luxembourg”, Bamako, Mali \\ ${ }^{2}$ ENT and Head and Neck Surgery Department, Reference Health Center, Bamako, Mali \\ ${ }^{3}$ Department of Stomatology and Maxillofacial Surgery, CHU-CNOS, Bamako, Mali \\ ${ }^{4}$ Department of Anesthesia Resuscitation, CHU Mother-Child "Luxembourg”, Bamako, Mali \\ ${ }^{5}$ ENT and Head and Neck Surgery Department, CHU Gabriel Toure, Bamako, Mali \\ Email: *ysidibe2002@gmail.com
}

How to cite this paper: Haidara, A.W., Sidibé, Y., Samaké, D., Coulibaly, A., Touré, M.K., Coulibaly, B.B., Soumaoro, S., Guindo, B., Diarra, K., Coulibaly, K., Sanogo, B., Kéita, M. and Mohamed, A.A. (2019) Tonsillitis and Their Complications: Epidemiological, Clinical and Therapeutic Profiles. International Journal of Otolaryngology and Head \& Neck Surgery, 8, 98-105.

https://doi.org/10.4236/ijohns.2019.83011

Received: February 15, 2019

Accepted: March 15, 2019

Published: May 10, 2019

Copyright $\odot 2019$ by author(s) and Scientific Research Publishing Inc. This work is licensed under the Creative Commons Attribution International License (CC BY 4.0).

http://creativecommons.org/licenses/by/4.0/

\begin{abstract}
Tonsillitis or angina, is considered as an inflammation of the palatine tonsils most often of infectious origin. It can be acute or chronic. The germs in question are mostly viruses and bacteria. Objectives: The objective of this work was to study the epidemiological and therapeutic profile of tonsillitis and their complications in the ENT Department and Head and Neck Surgery of the Mother-Child University Hospital in Luxembourg. Patients and Methods: This is a prospective study over a 12-month period from January 2018 to December 2018, including all patients who presented with tonsillitis and/or their complications. Results: Three hundred and fifteen (315) patients were collected during this period. The average age in our study was 14.25 years with extremes ranging from 2 years to 61 years. The sex ratio was 0.65 in favor of the female sex. During this period we recorded $80.95 \%$ of cases of uncomplicated tonsillitis including $60.50 \%$ for acute tonsillitis, $24.5 \%$ for chronic tonsillitis $5 \%$ for adenoid tonsillitis and $19.05 \%$ for complications. Complications included peritonsillar phlegmon $42.22 \%$, heart disease $33.33 \%$, cervical cellulitis $8.89 \%$, adeno-phlegmon $6.67 \%$, para-pharyngeal abscess $4.44 \%$, and sepsis $4.44 \%$. The exclusive medical treatment was performed in $44.31 \%$. Surgical treatment (drainage incision and tonsillectomy) was performed in $55.69 \%$. Conclusion: Tonsillitis and its complications represent an important pathology in ENT. Feynophagy febrile is the pair-origin symptom that can lead to the diagnosis. The prevention of complications is the guarantor of the
\end{abstract}


reduction of its morbidity. We recommend that in the absence of RDT (Rapid Diagnostic Test), it is necessary to systematize antibiotic therapy to prevent serious complications.

\section{Keywords}

Tonsillitis, Complication, Mali

\section{Introduction}

Tonsillitis is a public health problem because of its frequency, recurrence and socio-occupational and economic impact [1]. It is the 3rd infectious ENT pathology after rhinopharyngitis and otitis. These tonsillitis can generate complications that can be locoregional and/or general [2].

In Mali, tonsillitis accounts for $1.8 \%$ of the diseases encountered in ENT [3]. About 9 million new cases of tonsillitis are diagnosed in France each year [4]. In addition, the number of tonsillitis is estimated at 40 million per year in the US, 4 million in Spain, or more than 5\% of medical consultations in the US and $15 \%$ in Spain [5] [6] [7] [8].

Erythematous or erythemato-pultaceous tonsillitis is distinguished; pseudomembranous tonsillitis; ulcerous or ulceronecrotic tonsillitis and vesicular tonsillitis [9].

The definitive diagnosis of streptococcal infections is made by detection of the germ at the rapid diagnostic test (RDT) [10].

Although data on epidemiological and therapeutic aspects seem well established elsewhere, the fact remains that in some countries, such as Mali, much remains to be done. It is therefore important to take stock of this disease in our community. That is why we conducted this study to improve knowledge of the epidemiological, clinical and therapeutic aspects of tonsillitis and its complications.

\section{Patients and Method}

We carried out a retrospective study on a series of 315 cases of tonsillitis, collected in the Department of Otorhinolaryngology and Head and Neck Surgery (ENT and CCF) of CHU Mother-Child "Luxembourg", Bamako-Mali. It spanned a 12-month period from January 2018 to December 2018.

We included all patients admitted to outpatient or emergency outpatient care during the study period, whose clinical examination suggested tonsillitis or a complication of tonsillitis.

The variables studied were sociodemographic, clinical, para-clinical and therapeutic aspects. An effective ENT examination focused on the pharyngeal sphere was performed in all our patients. The diagnosis of tonsillitis and/or these complications was made on the basis of clinical, radiological and biological evi- 
dence of removal.

The data was processed by SPSS 21.0 French version and entered by Word 2013.

\section{Results}

Frequency: During the study period, we recorded 315 cases of tonsillitis including 255 cases of simple tonsillitis representing $80.95 \%$ and 45 cases of complication representing $19.05 \%$. During the study period 4500 patients consulted in ENT including 7\% for tonsillitis.

The female sex predominated with $60.63 \%$. The sex ratio was 0.65 in favor of the female sex. The 10 to 20 age group was the most common with $29.33 \%$ (Table 1). The average age was 14.25 years old with extremes ranging from 2 years old to 61 years old.

Clinically: Only odynophagia was the most frequent reason for consultation with $88.63 \%$.

We found other symptoms associated with type of fever (86.27\%) snoring (38.43\%) reflex otalgia (37.65\%) hyper-sialorrhea (20.39\%) dysphagia (15.29\%) sleep apnea syndrome (14.12\%) and dyspnea (10.20\%).

Oropharyngoscopy found bilateral hypertrophy of palatine tonsils in $82.35 \%$ of cases and inflammatory in $53.33 \%$ of cases.

The complication was observed in $19.05 \%$ of cases, ie 45 cases (Table 2). This complication was a tonsillar dephlegmon in 19 cases, parapharyngeal abscess in 2 cases, cervical cellulitis in 4 cases, adeno-phlegmon in 3 cases, and rheumatic complications with cardiopathy in 15 cases (Table 3).

The medical treatment was exclusive combining Antibiotic and analgesic in acute tonsillitis at $39.70 \%$. The surgical treatment associated with antidotics was performed in $60.30 \%$ of which $43.58 \%$ of the tonsillectomy.

\section{Discussions}

In 12 months, we collected 315 cases of tonsillitis, including 45 cases of

Table 1. Distribution of patients by age.

\begin{tabular}{ccc}
\hline Age group/year & Effective & Frequency\% \\
\hline$[0-10]$ & 90 & 28.57 \\
{$[10-20]$} & 92 & 29.21 \\
{$[20-30]$} & 68 & 21.59 \\
{$[30-40]$} & 43 & 13.65 \\
{$[40-50]$} & 15 & 4.76 \\
{$[50-65]$} & 7 & 2.22 \\
Total & 315 & 100
\end{tabular}


Table 2. Distribution of patients by type of complication N: 45 .

\begin{tabular}{lcc}
\hline Type of complication & Effective & Frequency \\
\hline $\begin{array}{c}\text { Local complication: } \\
\text { - Phlegmon peritonsillar } \\
\text { Loco-regional complications: }\end{array}$ & 19 & 42.22 \\
- Cervical cellulitis & 4 & \\
- Adeno-cellulitis & 3 & 8.89 \\
- Pharyngeal abscess & 2 & 6.67 \\
General complications: & 2 & 4.44 \\
- Heart & 15 & 33.33 \\
- Sepsis & 2 & 4.44 \\
Total & 45 & 100 \\
\hline
\end{tabular}

Table 3. The distribution of patients according to type of cardiac disease found N: 15 .

\begin{tabular}{ccc}
\hline Type of heart disease & Effective & Frequency \\
\hline Mitral insufficiency (MI) & 6 & 40.00 \\
Mitral recess (RM) & 2 & 13.33 \\
Aortic insufficiency (IAo) & 2 & 13.33 \\
IM/Tripuscudian insufficiency & 2 & 13.33 \\
IM/IAo & 3 & 20.00 \\
Total & 15 & 100.00 \\
\hline
\end{tabular}

complications; a respective frequency of $7 \%$ and $0.33 \%$ of the consultants during the study period. In the United Kingdom in 2009 tonsillitis was found with an incidence of 100 per 1000 inhabitants [11] and peritonsillar phlegmon was found with an incidence of 12/100,000 [12]. The possibility of a complication of acute tonsillitis seemed to us frequent in practice, this is explained by the nonobservance of the medical treatment by the patients on the one hand and on the other hand the maladaptive management of tonsillitis, cause the evolution of this pathology is cascading. We believe that a multicentric study may identify more tonsillitis and complications.

Tonsillitis and its complications can occur at any age [1] [13]. In our series, the extreme ages were 2 years old and 61 years old. Similarly, $82.35 \%$ of our patients were under 30 years of age, which is consistent with the TIMBO SK [3] study, where $67.74 \%$ of patients were $<30$ years of age. The most representative age group was that of 10 to 20 years with $29.21 \%$ of cases in our series. It was the same at SOWERBY et al. [12].

Frequency in this age group may be explained by increased exposure to rhinopharyngitis episodes associated with immune failure at this age. At this age tonsillitis is discovered in consultation with children consulting for otalgia, or for cries incessant. 
The complications are predominant in the age group 20 to 30 years with a frequency of $39.13 \%$. According to DULGUEROV [14] this age group is 20 to 40 years old.

In our series, we observed a slight predominance of women (60.63\%). This is in line with TIMBO SK [3], which contributed $72.03 \%$. Other authors have found a male predominance [1]. According to the literature, the predominance of sex has no impact on the occurrence of tonsillitis [15].

All professional classes were represented in our study. The student and student status was the most represented profession (45.88\%) because it also falls in the youth category (49.7\%) [16]. We believe that the high mobility of this population can be a determining factor. Elsewhere their promiscuity can be a factor.

As odynophagia is the main sign of tonsillitis, it was found in $88.63 \%$ of our patients. We found other symptoms associated with type of fever (86.27\%), snoring (38.43\%), reflex otalgia (37.65\%), hyper-sialorrhea (20.39\%), dysphagia (15.29\%), sleep apnea syndrome (14.12\%) and dyspnea (10.20\%). TIMBO SK [3] found a predominance of odynophagia-fever association with $42.3 \%$.

The duration of evolution of tonsillitis and its complications has been little discussed in the literature. The short duration of evolution is linked to an early consultation in the hospital by patients who came for consultation on their own, hence the treatment was instituted immediately according to the recommendations of the AFSSAPS [11].

The long duration of tonsillitis is explained by the lack of observance of the medical treatment instituted on the one hand, and the maladjustment of antibiotic therapy, which does not respect the recommendations of the AFSSAPS. These observations note the cascade evolution of the infection, its maintenance and the passage from several acute tonsillitis to chronic tonsillitis and even complications. The mode of recruitment of tonsillitis testifies this because $16.86 \%$ were referred and the clinical history of these patients highlighted the nonobservance and the maladjustment of the antibiotherapy not respecting the current recommendations.

In our study uncomplicated tonsillitis was found with $90 \%$ and complicated tonsillitis was $10 \%$. TIMBO SK [3] found respectively $75.8 \%$ and $24.2 \%$. A Cotonou [15] tonsillitis was acute in $45.99 \%$ and was complicated in $54.01 \%$ including recurrent tonsillitis with $25.26 \%$ and chronic tonsillitis with $19.16 \%$.

It can be said that tonsillitis is initially simple but they can be complicated by the delay or maladjustment of the treatment, the immune status and the virulence of the germ in question.

According to the literature review the peritonsillar phlegmon is the main complication of tonsillitis and $2.4 \%$ of annual consultations in urgency [17]. This observation corroborates with our study of which $42.22 \%$ was represented by phlegmon. The incidence of these complications represented $2 / 1000$ in the study of PIERRE RABANY [18] in 2003. In the United Kingdom [2] the peritonsillar phlegmon was found with an incidence of 12/100,000 in 2013.

Heart disease accounted for $33.33 \%$ of complication in our study. Isolated mi- 
tral regurgitation was the most common heart disease with $40 \%$. This result is similar to that of de Maiga. S [19] who found isolated mitral regurgitation at $43.30 \%$ greater than that of Coulibaly. E [20] who had regained isolated mitral insufficiency $15.38 \%$.

Other complications in our study included cervical cellulitis (13.33\%), adenophlegmon (10\%), para-pharyngeal abscess (6.67\%), sepsis (6.67\%), the TIMBO SK study [3] the same complications were found.

According to the literature the antibiotic management of tonsillitis is well codified, based on the detection of group A hemolytic streptococcus by TDR. The AFSSAPS [11] updated the recommendations concerning this treatment by proposing to treat only proven tonsillitis with $\mathrm{S} \beta \mathrm{HA}$ and by favoring the use of beta-lactams in short treatment.

The difficulty lies in the differentiation of viral and bacterial tonsillitis in our context because we do not currently have the TDR. We have recommended treating all cases of tonsillitis systematically with antibiotics, which is in line with the current recommendations in France, which is to systematically treat acute tonsillitis with antibiotics [21].

Medical treatment was exclusive at $39.70 \%$ in our study compared to a study in Cotonou [15] where medical treatment was instituted in $45.99 \%$. We used beta-lactams and macrolides, duration of antibiotic therapy ranged from 7 to 10 days.

This surgical treatment involved tonsillectomy $43.58 \%$, incision and drainage in $16.86 \%$. In France [22], out of approximately 670,000 annual anesthesia in ENT, $17 \%$ are for tonsillectomies.

These indications included recurrent acute tonsillitis, complications and obstructive tonsillitis. This observation corroborates the study of YAHYAOUI M [22]. In England and Wales more than 50,000 tonsillectomies have been performed, most of them involving recurrent tonsillitis [23].

\section{Conclusions}

Tonsillitis and its complications represent an important pathology in ENT. Tonsillitis occurs in the majority of cases in children and young adults particularly between 20 and 30 years with a slight predominance of women.

Odynophagia is the most frequent warning sign. Peritonsillar phlegmon is recognized as the most frequent complication. The diagnosis of tonsillitis and its complications are essentially clinical. The medical treatment of acute tonsillitis is well codified based on the detection of streptococcus by TDR. The indications of the surgical treatment are well defined.

\section{Conflicts of Interest}

The authors do not declare any conflict of interest.

\section{References}

[1] Barry, B., Gehanno, P. and Tran bay, P. (1999) Infectious and Inflammatory Pa- 
thology of the Adult. Editions Ellipses, Paris, 448.

[2] Beatrix, B., Roman, K. and Christian-Adrien, R. (2014) Pharyngeal Infections. The Amplifon Monographs, Paris, No. 56.

[3] Timbo, S.K., Keita, M.A., Togola, F.K., Traore, L. and Mohamed, A. (2006) Epidemiological Aspects of Angina in Bamako. Mali Med, TXXI N 4.

[4] Crampette, L. (1998) Angina, Encycl Med Chir, ENT Generalist Manual. Elsevier, Paris, $4 \mathrm{p}$.

[5] Nash, D.R., et al. (2002) Antibiotic Prescribing by Primary Care Physicians for Children with Upper Respiratory Tract Infections. Archives of Pediatrics and Adolescent Medicine, 156, 1114-1119. https://doi.org/10.1001/archpedi.156.11.1114

[6] Bisno, A.L. and Kaplan, E.L. (2006) Strep Throat Over and Over: How Frequent? How Real? Mayo Clinic Proceedings, 81, 1153-1154.

https://doi.org/10.4065/81.9.1153

[7] Shaikh, N., Leonard, E. and Martin, J.M. (2010) Prevalence of Streptococcal Pharyngitis and Streptococcal Carriage in Children: A Meta-Analysis. Pediatrics, 126, e557-e564. https://doi.org/10.1542/peds.2009-2648

[8] Dagnelie, C.F., Touw-Otten, F., Kuyvenhoven, M.M., et al. (1993) Bacterial Flora in Patients Presenting with Sore Throat in Dutch General Practice. Family Practice, 10, 371-377. https://doi.org/10.1093/fampra/10.4.371

[9] Albert, S. and Bozec, H. (2002) Angina: ENT and Head and Neck Surgery. Editions Ellipses, Paris, $175-186$.

[10] French Agency for Health Safety of Health Products (AFSSAPS) (2005) Antibiotic Therapy in General Practice: ENT and Respiratory Infections Low. Sharp Angina. Syntheses. Recommendations.

[11] Sowerby, L.J., Hussain, Z. and Murad, H. (2013) The Epidemiology, Antibiotic Resistance and Post-Discharge Course of Peritonillar Abscesses in London, Ontario. Journal of Otolaryngology-Head and Neck Surgery, 42, 5. https://doi.org/10.1186/1916-0216-42-5

[12] Loganathan, A., Arumainathan, U.D. and Raman, R. (2006) Comparative Study of Bacteriology in Recurrent Tonsillitis among Children and Adults. Singapore Medical Journal, 47, 271-275.

[13] Georgalas, C.C., Tolley, N.S. and Narula, A. (2009) Tonsillitis. BMJ Clinical Evidence, 2014, pii: 0503.

[14] Dulguerov, P., Landis, B. and Giger, R. (2014) Peritonsillar Abscess. Development, Otorhinolaryngology: Swiss Medical Review, No. 2500.

[15] Chobli, M., Yehouessi-Vignikin, B., Zoumenou, E., et al. (2012) Support for Children's Tonsillitis in ENT at CNHU Cotonou. R.A.M.U.R, Volume $17 \mathrm{n}^{\circ} 1$.

[16] Camara, Y. (2008) The Civil Status Census Launched in Mali, the Independent of October 29.

[17] Koffi-Aka, V., Adjoua, R.P., Kouassi, B., et al. (2007) Peritonsillar Phlegmon in Abidjan: Clinical Case. The Letter of ENT and Head and Neck Surgery, No. 311, 26-28.

[18] Rabany, P., Lepoutre, B. and Aubert, J. (2003) TDR: When to Use It? The Review of the Practitioner-General Medicine. Vol. 17, 1581-1584.

[19] Maiga, S. (2012) Hospital Prevalence of Rheumatic Heart Disease at the Mother-Child Hospital Luxembourg. [Bamako (Mali)]. 2011-2012. Thesis of Medicine.

[20] Coulibaly, E. (2015) Cardiac Complications of Throat. [Bamako (Mali)] INFSS.

[21] Essomba, E.N., Bita Fouda, A., Ngaba, G.P., et al. (2013) Efficacy of Antibiotics in 
Post Tonsillectomy in Sub-Saharan Africa: Case of Laquintinie Hospital in Douala. Vol. 14.

[22] Orliaguet, G. (2008) Anesthesia for Tonsillectomy in Children. French Annals of Anesthesia and Resuscitation, 27, 200-201.

[23] Toh, A., Mullin, A., Grainger, J. and Uppal, H. (2009) Indications for Tonsillectomy: Are We Documenting Them? Annals of the Royal College of Surgeons of England, 91, 697-699. https://doi.org/10.1308/003588409X12486167521712 